\title{
Comparative morbidity data in primary care - the Northumberland MEDICS Project
}

Richard Edwards Evidence for Population Health Unit, University of Manchester, Manchester, UK Paul Murphy, Kevin J Allan, Sue Gordon Northumberland Health Authority, Morpeth, UK and Stephen Singleton Department of Epidemiology and Public Health, School of Health Sciences, University of Newcastle, Newcastle upon Tyne, UK and Northumberland Health Authority, Morpeth, UK

\begin{abstract}
There is increasing interest in collecting morbidity data from general practice. We describe our experience from Northumberland MEDICS, one of the first morbidity data collection projects in the UK. All Northumberland practices were invited to participate. Data were initially collected every 3-6 months and included the prevalence of chronic diseases, disability in the over $75 \mathrm{~s}$, and recording of health markers, such as smoking status. Thirty-three out of 52 practices participated. There was marked variation in prevalences and recording of health markers between practices. Recorded prevalence of hypertension and diabetes increased steadily from 1994 to 1998. Outcomes, judged by the original objectives, were mixed. However, as the project evolved, evidence emerged that MEDICS was contributing to a culture in which the use of data from practice clinical systems to improve patient care has become a core objective. Key lessons from our experience include appreciating: the importance of data quality and minimising workload for practices; the difficulties practices face in recording morbidity data consistently and systematically; the limitations of GP morbidity data for health needs assessment and commissioning at district level; and the need to focus on providing useful and relevant data for individual practices. MEDICS now covers all 53 Northumberland practices. The project focuses on recording and analysing data to help practices improve structured patient care. Increasingly data collection in general practice in Northumberland is seen as a core activity with the current dataset linking closely with local priorities and reflecting national initiatives such as Clinical Governance and National Service Frameworks.
\end{abstract}

Key words: audit and feedback; clinical information, data extraction; general practice; MIQUEST; quality of care

\section{Introduction}

In recent years in the United Kingdom, there has been a strategic shift towards a primary care-led National Health Service (NHS) (Department of Health, 1996, 1997, 1998; NHS Management Executive, 1994), and a focus on improving the quality of health care through mechanisms such as clinical audit, improving clinical effectiveness and Clinical Governance (Department of Health, 1999;

Address for correspondence: Dr Richard Edwards, Department of Epidemiology and Public Health, School of Health Sciences, The Medical School, University of Newcastle, Newcastle upon Tyne, NE2 4HH, UK. Email: p.r.edwards@ncl.ac.uk
NHS Executive, 1996a, 1996b). These developments together with the increasing computerisation of general practice (Department of Health, 1993), and the information requirements of practice-led purchasing and commissioning initiatives like Primary Care Groups, Personal Medical Services pilot practices and Fundholding general practice have created interest in the use of routine data from practice clinical systems. This is underlined by the existence of a national project to facilitate the establishment of schemes to collect, analyse and make use of health data stored on general practice (GP) clinical systems (Collection of Health Data from General Practice project, 1996).

Several schemes piloting the collection and use 
of morbidity data from primary care began in the UK in the late 1980s or early 1990s. The following is a brief overview of five schemes which had published their findings by 1996. The approaches taken varied widely. Most were district- (Klein, 1996; Pearson etal., 1996; Wilson et al., 1995) or locality-based schemes (Daniels, 1995). One was regionally based (Boydell et al., 1995). Some used volunteer practices (Daniels, 1995; Klein, 1996; Wilson et al., 1995), whilst others recruited practices selectively to be representative of practices and the population of the study area (Boydell et al., 1995; Pearson et al., 1996). The schemes used episode (largely consultation-based) data, or extracted recorded diagnoses or lifestyle information, such as smoking status and alcohol intake. Some used both approaches. One scheme reported incidence data only (Boydell et al., 1995), three reported only or mainly prevalence data (Daniels, 1995; Klein, 1996; Wilson et al., 1995), and one reported both (Pearson et al., 1996). The scope of data collection varied from the recording and analysis of all consultations (Pearson et al., 1996) to a scheme which focused only on reporting the prevalence of six common chronic conditions (Klein, 1996). Two projects collected data by computerised extraction (Boydell et al., 1995; Pearson et al., 1996). The other three used a mix of computerised extraction and manual completion of paper record forms. Data were collated centrally in all the schemes, often by the health authority. It was then fed back with individual practices having their data highlighted, and other practice data anonymised.

The Northumberland Morbidity and Epidemiology Data Interchange and Comparison Scheme (MEDICS) was another early district-based project to collect morbidity data from general practice. This paper describes the first 8 years' experience, the lessons learnt and how this shaped our thinking about the collection and use of data from general practice.

\section{Method}

\section{Origins and objectives}

MEDICS was an exploratory project originating from a joint information strategy between the Family Health Services Authority (FHSA), District Health Authority and General Practices in 1991. The project board included health authority and
FHSA staff, GPs and a practice manager. The project began in June 1992 and built on previous work demonstrating the potential for data collection from general practice. This included monitoring of immunisation uptake in Northumberland practices, with feedback of individual and comparative data (Colver, 1990), and a survey of diabetes prevalence and the availability of diabetes and other chronic diseases prevalence data in 48 of 50 Northumberland practices in 1991 (Gordon, 1991).

Initial objectives were to explore the collection of data to assist the FHSA and health authority in assessing health needs and promoting service developments, and to encourage the process of structured collection and analysis of morbidity data in general practice. Unlike many of the other projects described above, MEDICS aimed to be inclusive by maximising the number of practices participating, rather than focusing on practices with well-organised data management systems. Experience from the initial work in Northumberland suggested that difficulties with data extraction and data quality were likely and hence the objectives might take many years to achieve.

\section{Data collection and analysis}

All 52 practices in Northumberland were invited to participate. Practices were paid a small fee, initially 40p per registered patient per year, for providing aggregated data in three categories:

1. Prevalence of chronic diseases including: cancers, asthma, stroke and ischaemic heart disease, hypertension, diabetes and hypothyroidism. For diabetes and asthma, the proportions receiving defined categories of treatment were also included.

2. Recording and prevalence of 'health markers' including: alcohol intake, body mass index, family history of ischaemic heart disease, smoking status and blood pressure recording in the last 10 years. Those with recorded information were divided into risk categories, for example, the proportion of current, ex- and nonsmokers.

3. Recording and prevalence of disability in the over $75 \mathrm{~s}$ : including the proportion with records of vision, hearing, cerebral functioning, urinary continence and mobility; and for each the proportion of those with records, with 'no significant', 'moderate' or 'severe' impairment. 
The categories chosen largely reflected the likely availability of data. This was based on information from the diabetes survey demonstrating widespread availability of prevalence data on diabetes and other chronic diseases, and known data recording requirements stemming from the new GP contract (particularly 'health promotion' and 'chronic disease' clinics, and annual assessments of patients aged over 75 years).

Data categories were introduced in stages. Each was piloted in three practices using different clinical information systems. Data collection initially occurred every 3 months using standardised data collection forms. These were completed manually, or more often, by using the reporting module of the practice clinical system to provide denominator and numerator data. Case definitions were largely based on GPs' working diagnoses and assessments. However, guidance was given for the assessment and categorisation of degrees of disability.

Data were entered centrally on to a computerised database. For chronic diseases, crude prevalence and standardised morbidity ratios for men and women were reported by practice. The latter were indirectly age-standardised prevalence ratios calculated using mean prevalences for 10 year age bands from all MEDICS practices combined. The recording of health markers and disability, and the proportion of those with records within each risk or disability category was calculated.

\section{Reporting and feedback}

Feedback reports were circulated to all practices after each data collection. These included bar charts and tables showing individual practice data in relation to anonymised data for the other MEDICS practices (Figure 1). Values for individual practices remained confidential except to the relevant primary health care team.

\section{Results}

\section{Participating practices}

Thirty-four practices initially took part. By April 1996, 33 practices were participating, covering 221000 people - almost three-quarters of Northumberland's population. These practices used nine different general practice clinical systems and five different coding schemes. The dataset at each data collection point was never complete due to one or more practices not participating and individual participating practices failing to return data on all categories within the dataset.

MEDICS practices were slightly larger, more rural, and more likely to be fundholders or training practices than non MEDICS practices (Table 1). The most under-represented localities were the largely urban and socio-economically disadvantaged areas of Wansbeck and Blyth. The age structure of the population of MEDICS practices was almost identical to that of the Northumberland population.

Illustrative data are shown from March and September 1995. Prevalences of chronic disease, recording of health markers, and the marked interpractice variation in these are shown in Tables 2 and 3. The proportion of adults aged over 75 years with disability data recorded at MEDICS practices in September 1995 ranged from $55.9 \%$ for urinary continence to $70.8 \%$ for hearing. Of those with recorded data, the proportion with moderate impairment for disability markers varied from 5.4\% for cerebral functioning to $27.1 \%$ for mobility, and for severe impairment from $2.5 \%$ for continence to $5.5 \%$ for vision. Changes in prevalence rates of three chronic diseases between 1994 and 1998 are shown in Table 4. These data are taken from 18 practices which provided prevalence data for all three conditions each year.

\section{Evaluation, outcomes and development of the MEDICS project}

A preliminary independent evaluation involving interviews with staff at 20 practices was carried out in 1993 (Maguire et al., 1994). The report confirmed the project board's fears about the difficulty of achieving the project objectives in the short term. MEDICS data had had little input into needs assessment or the commissioning process, was poorly linked with other data for locality planning and the health authority's planning cycle, and was little used by the public health directorate. However, the data did influence the authority's medium-term strategy which adopted stroke prevention, treatment and rehabilitation as a priority. A policy of developing Northumberland guidelines for the management of chronic diseases like hypertension was introduced in the knowledge that there would be the capacity to monitor progress.

Practices described several benefits from participation in MEDICS. For example, a third of practices reported that MEDICS data had stimulated 


\section{Hypertension prevalence}

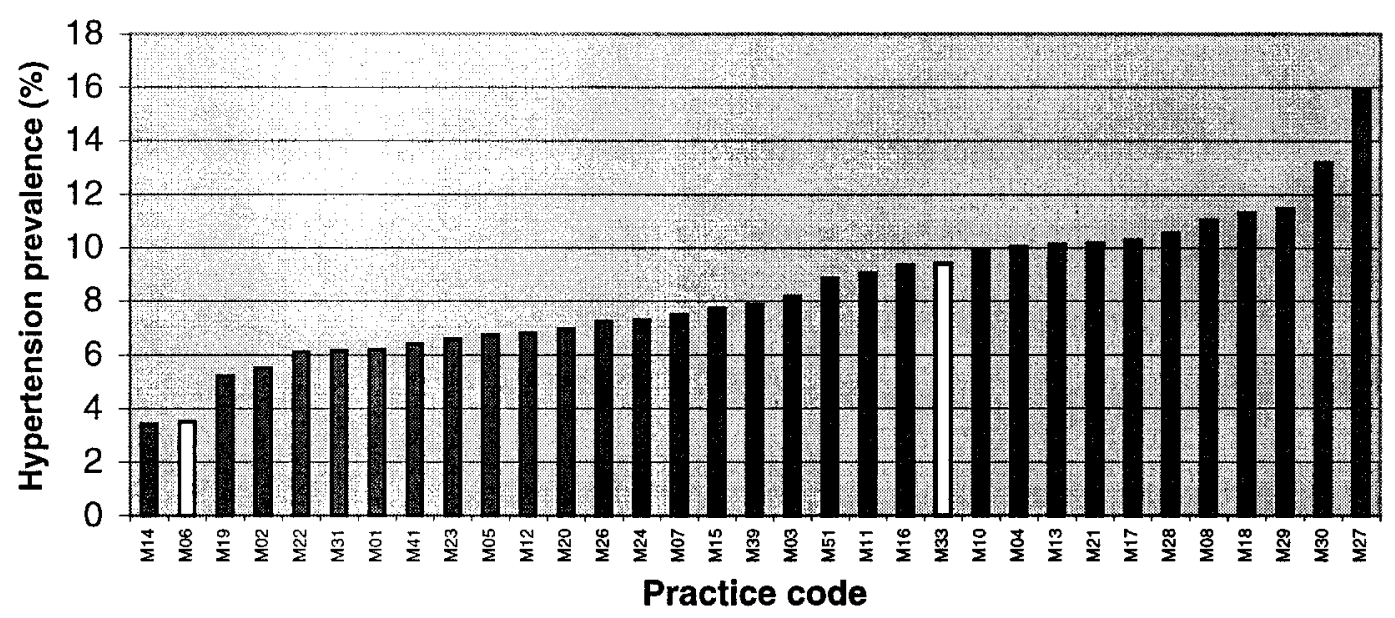

Hypertension - standardised morbidity ratios (SMR)

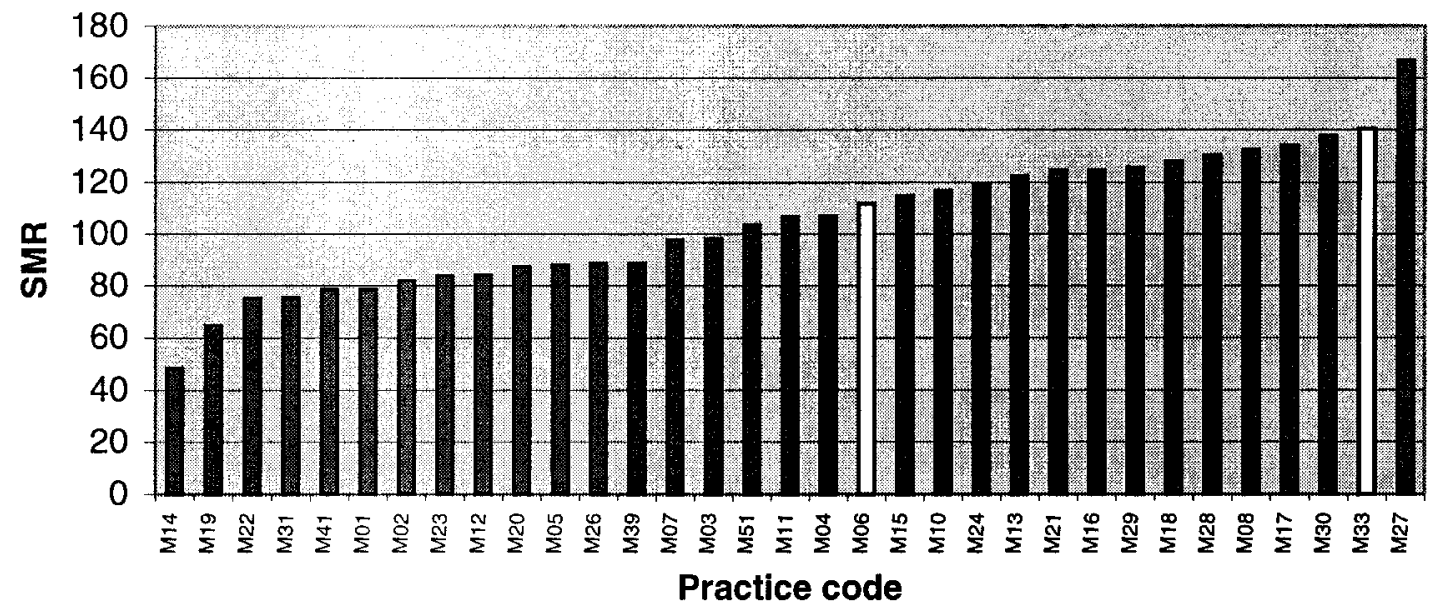

Figure 1 Hypertension prevalence and standardised morbidity ratios among women at 33 MEDICS practices, September 1995.

improvements in data management at the practice. Nearly all practices felt MEDICS had made them appreciate the capabilities and limitations of their clinical systems. A few thought that MEDICS data had stimulated audit and one practice claimed to be using the data in strategic planning. However, the evaluation also revealed limitations to the impact of MEDICS at practice level. Over a quarter of practices stated that feedback reports were little used. The most common reported use was for administrative requirements such as compiling health promotion banding returns and practice annual reports.

The evaluation also confirmed some of the anticipated problems with data collection. Practices expressed concerns about the workload in collecting the data; the length and complexity of the feedback reports; the accuracy of the data; and the 
Table 1 Characteristics of 33 MEDICS practices

\begin{tabular}{lcc}
\hline & $\begin{array}{l}\text { MEDICS } \\
\text { practices }\end{array}$ & $\begin{array}{l}\text { All Northumberland } \\
\text { practices }\end{array}$ \\
\hline Mean list size & 6707 & 5843 \\
Average number of GPs per practice & 4.2 & 3.6 \\
Average numbers of patients per GP & 1607 & 1606 \\
Average numbers of practice nurses per practice & 3.2 & 3.4 \\
Average number of other practice staff per practice & 15.7 & 16.1 \\
Proportion of female GPs & $28 \%$ & $25 \%$ \\
Proportion of GPs <40 years & $43 \%$ & $42 \%$ \\
Proportion of post-graduate training practices & $66 \%$ & $49 \%$ \\
Proportion of fundholding practices & $44 \%$ & $33 \%$ \\
Proportion of practices in receipt of rural practice payments & $59 \%$ & $47 \%$ \\
\hline
\end{tabular}

Table 2 Median, mean and ranges of prevalences for chronic diseases in 33 MEDICS practices in September 1995

\begin{tabular}{|c|c|c|c|c|}
\hline & \multicolumn{2}{|c|}{$\begin{array}{l}\text { Median (mean) prevalence } \\
\text { in cases per } 100 \text { persons }\end{array}$} & \multicolumn{2}{|c|}{$\begin{array}{l}\text { Range (interquartile range) of } \\
\text { prevalences in cases per } 100 \text { persons }\end{array}$} \\
\hline & Males & Females & Males & Females \\
\hline $\begin{array}{l}\text { Asthma } \\
(n=30)\end{array}$ & $5.6(5.8)$ & $5.6(5.7)$ & $\begin{array}{l}1.4-13.1 \\
(4.4-7.1)\end{array}$ & $\begin{array}{l}1.3-13.4 \\
(4.1-6.6)\end{array}$ \\
\hline Diabetes & $2.0(2.0)$ & $1.6(1.6)$ & $\begin{array}{l}0.8-4.1 \\
(1.7-2.3)\end{array}$ & $\begin{array}{l}0.8-2.9 \\
(1.3-1.8)\end{array}$ \\
\hline Stroke & $1.4(1.4)$ & $1.3(1.4)$ & $\begin{array}{l}0.4-4.2 \\
(1.0-1.7)\end{array}$ & $\begin{array}{l}0.4-3.2 \\
(0.9-1.6)\end{array}$ \\
\hline Hypertension & $5.8(6.0)$ & $7.8(8.4)$ & $\begin{array}{l}2.4-12.0 \\
(5.1-6.8)\end{array}$ & $\begin{array}{l}3.4-15.9 \\
(6.5-10.1)\end{array}$ \\
\hline Ischaemic heart disease & $5.0(5.0)$ & $4.3(4.1)$ & $\begin{array}{l}1.9-7.2 \\
(4.3-6.1)\end{array}$ & $\begin{array}{l}1.4-6.8 \\
(3.2-5.0)\end{array}$ \\
\hline
\end{tabular}

Table 3 Population coverage for health markers at 29 MEDICS practices in March 1995

\begin{tabular}{|c|c|c|c|c|}
\hline & \multicolumn{2}{|c|}{ Median (mean) coverage $\%$} & \multicolumn{2}{|c|}{ Range (interquartile range) \% } \\
\hline & Males & Females & Males & Females \\
\hline Alcohol status & $46.4(45.5)$ & $54.9(51.4)$ & $\begin{array}{l}10.8-73.2 \\
(35.4-57.3)\end{array}$ & $\begin{array}{l}20.4-72.6 \\
(42.0-64.6)\end{array}$ \\
\hline Smoking status & $56.7(50.9)$ & $66.8(61.6)$ & $\begin{array}{l}21.3-69.7 \\
(41.4-60.9)\end{array}$ & $\begin{array}{l}36.6-76.6 \\
(51.4-70.1)\end{array}$ \\
\hline Blood pressure & $54.6(54.9)$ & $69.2(67.4)$ & $\begin{array}{l}27.8-77.1 \\
(50.0-64.3)\end{array}$ & $\begin{array}{l}41.1-84.8 \\
(62.1-75.3)\end{array}$ \\
\hline $\begin{array}{l}\text { Family history of IHD } \\
(n=26)\end{array}$ & $25.8(32.7)$ & $38.6(41.3)$ & $\begin{array}{l}2.8-82.7 \\
(19.6-47.4)\end{array}$ & $\begin{array}{l}2.7-81.2 \\
(28.5-58.4)\end{array}$ \\
\hline $\begin{array}{l}\text { Body mass index } \\
(n=28)\end{array}$ & $41.6(40.7)$ & $56.3(52.3)$ & $\begin{array}{l}14.9-62.1 \\
(31.7-48.0)\end{array}$ & $\begin{array}{l}20.3-68.9 \\
(48.2-61.6)\end{array}$ \\
\hline
\end{tabular}


Table 4 Prevalence of chronic diseases in MEDICS practices 1994-1998

\begin{tabular}{|c|c|c|c|c|c|c|c|c|c|c|c|}
\hline & \multirow{2}{*}{$\begin{array}{l}\text { Number of } \\
\text { practices }^{\mathrm{a}}\end{array}$} & \multicolumn{5}{|c|}{ Number of cases (denominator) } & \multicolumn{5}{|c|}{ Prevalence (\%) } \\
\hline & & 1994 & 1995 & 1996 & 1997 & 1998 & 1994 & 1995 & 1996 & 1997 & 1998 \\
\hline \multicolumn{12}{|l|}{ Males } \\
\hline Diabetes & 18 & $\begin{array}{l}1106 \\
(63047)\end{array}$ & $\begin{array}{l}1217 \\
(62855)\end{array}$ & $\begin{array}{l}1320 \\
(62595)\end{array}$ & $\begin{array}{l}1474 \\
(64476)\end{array}$ & $\begin{array}{l}1617 \\
(65293)\end{array}$ & 1.8 & 1.9 & 2.1 & 2.3 & 2.5 \\
\hline Hypertension & 16 & $\begin{array}{l}2830 \\
(51313)\end{array}$ & $\begin{array}{l}2963 \\
(51082)\end{array}$ & $\begin{array}{l}3359 \\
(50802)\end{array}$ & $\begin{array}{l}3810 \\
(52794)\end{array}$ & $\begin{array}{l}3983 \\
(53499)\end{array}$ & 5.5 & 5.8 & 6.6 & 7.2 & 7.4 \\
\hline $\begin{array}{l}\text { Ischaemic } \\
\text { heart disease }\end{array}$ & 17 & $\begin{array}{l}2944 \\
(56696)\end{array}$ & $\begin{array}{l}2898 \\
(56484)\end{array}$ & $\begin{array}{l}2946 \\
(56206)\end{array}$ & $\begin{array}{l}2871 \\
(58222)\end{array}$ & $\begin{array}{l}2957 \\
(58963)\end{array}$ & 5.2 & 5.1 & 5.2 & 4.9 & 5.0 \\
\hline \multicolumn{12}{|l|}{ Females } \\
\hline Diabetes & 18 & $\begin{array}{l}992 \\
(66499)\end{array}$ & $\begin{array}{l}1097 \\
(66440)\end{array}$ & $\begin{array}{l}1153 \\
(66109)\end{array}$ & $\begin{array}{l}1322 \\
(67811)\end{array}$ & $\begin{array}{l}1416 \\
(69651)\end{array}$ & 1.5 & 1.7 & 1.7 & 2.0 & 2.1 \\
\hline Hypertension & 16 & $\begin{array}{l}4129 \\
(54227)\end{array}$ & $\begin{array}{l}4224 \\
(54114)\end{array}$ & $\begin{array}{l}4795 \\
(53831)\end{array}$ & $\begin{array}{l}5443 \\
(55741)\end{array}$ & $\begin{array}{l}5709 \\
(56494)\end{array}$ & 7.6 & 7.8 & 8.9 & 9.8 & 10.1 \\
\hline $\begin{array}{l}\text { Ischaemic } \\
\text { heart disease }\end{array}$ & 17 & $\begin{array}{l}2689 \\
(59840)\end{array}$ & $\begin{array}{l}2450 \\
(59753)\end{array}$ & $\begin{array}{l}2500 \\
(59446)\end{array}$ & $\begin{array}{l}2202 \\
(61316)\end{array}$ & $\begin{array}{l}2251 \\
(62120)\end{array}$ & 4.5 & 4.1 & 4.2 & 3.6 & 3.6 \\
\hline
\end{tabular}

${ }^{a}$ Eighteen practices took part in data collections during each year from 1994 to 1998, where data are available for less than 18 practices, this is due to practices not returning data for a specific disease in 1 or more years.

usefulness of some data - particularly the disability information (due to perceived subjectivity in assessing disability). An important reason given for the lack of use of MEDICS data within practices was concern about data quality. Practice visits by the project facilitator in 1994 confirmed the problems with data accuracy, and revealed variations between practices in data recording (typically due to variations in definitions and coding) and data extraction procedures. Steps taken to address these problems are shown in Box 1.

The difficulty of extracting data from clinical information systems was a spur to the development of MIQUEST, a set of data extraction tools, including a query language, allowing the extraction of a common dataset from different GP clinical systems (Allan et al., 1994; Allan, 1994). Use of MIQUEST encourages the standardisation of data recording and coding, facilitates standardised data extraction procedures, and minimises the workload for practices. Much of the exploratory work for MIQUEST was carried out in MEDICS practices. MIQUEST is now accepted by the NHS Executive as the preferred method for extracting data from

\section{Box 1 Improvements to MEDICS to address problems uncovered by 1994 evaluation}

- Reduction in workload for practices by collecting data every 6 months, and substantially reducing the dataset (e.g. by dropping cancers and hypothyroidism, and later disability data)

- Feedback report simplified, shortened, and an explanatory commentary added

- Improvements in data quality and comparability by issuing a data collection guide with standardised coding definitions and data extraction procedures

- Reductions in workload and data quality improvements through use of MIQUEST software to extract data at practices with MEDITEL and EMIS clinical systems (17 practices by September 1994, 49 by June 2000). 
GP clinical systems (NHS Information Management Centre, 1997).

Between 1994 and 1998 outcomes were much more positive and the project coincided with vigorous efforts to improve primary care prevention and management of common chronic diseases like hypertension, stroke and heart disease in Northumberland. This occurred through guideline development and implementation (Aylett et al., 1997), district-wide audits (Northumberland Primary Care Audit Group, 1996, 1997), and training initiatives. The exact contribution of MEDICS to these efforts is difficult to determine, but we believe the methods developed in MEDICS facilitated the work and that MEDICS contributed to a culture in which the use of general practice clinical systems to improve patient care became a core objective.

For example, in 1996, a data completeness audit was performed in nine practices (Northumberland Primary Care Audit Group, 1996). The recording of five chronic diseases and blood pressures in handwritten notes and computerised records was compared, using MIQUEST for data extraction from the latter. In 1995 and 1997, there were district-wide audits of hypertension care involving 32 practices and 20 practices (Northumberland Primary Care Audit Group, 1997). This work could not have been done without the preparatory experience from MEDICS. In response to the variation in hypertension prevalence demonstrated through MEDICS, a training project was undertaken in 1998 to improve hypertension data on practice clinical systems. This focused on improving coding and recording of data, performing retrospective work to clean existing data, and running reports on levels of defaulting and data quality issues. Seventy-five staff from 34 practices took part in the training.

Individual practices have been stimulated by MEDICS data to improve data quality, and hence hopefully quality of care. For example, one practice with one of the lowest prevalence rates for hypertension in 1996 responded by searching written records to 'find' missing hypertensive patients. As a result the crude prevalence increased from 4.4 to $7.6 \%$ between August 1996 and March 1997. This represented an increase in the number of recorded hypertensives from 625 to 1077 . The steady increase in recorded prevalence of hypertension and diabetes (Table 4) at MEDICS practices suggests that marked improvements in identification and recording of these chronic diseases has occurred at MEDICS practices.

\section{Discussion}

MEDICS has demonstrated that general practice morbidity data collection from a wide range of practices is achievable and sustainable, and can stimulate audit and improvements in data quality in practices. Since identification and recording of patients with chronic diseases is essential for ongoing follow-up and structured disease management (Tudor-Hart, 1993), this should in itself result in improved patient care.

We have drawn several key lessons from MEDICS, many of which are mirrored by the experience of other general practice morbidity data collection schemes. The first is the importance of data quality. The experience from MEDICS and similar projects (Boydell et al., 1995; Daniels, 1995; Klein, 1996; Pearson et al., 1996; Wilson et al., 1995) is that in the initial stages data quality is often the overriding issue in interpretation and establishing the credibility of general practice data. Until data quality is addressed, the data are of little use for improving patient care, or planning and strategy development work at any level.

Secondly, we now appreciate better the difficulties practices have in recording morbidity data systematically and consistently, and the workload maintaining data quality entails for project administrators and practice staff. This has implications for the quality of chronic disease management in primary care. The use of MIQUEST has helped us to address these issues at practices with compatible clinical information systems. The degree to which the high level of participation in MEDICS reflected payment for data is unclear. However, if, as in MEDICS, maximising participation is important, then payment for data may be required to compensate practices for the additional workload, particularly in the early stages when the benefits are perceived as uncertain. MIQUEST is 
now used for data extraction for MEDICS in 49 out of 53 practices, so the workload implications of data collection for participating practices are now much reduced.

Work continues to improve data quality and facilitate the collection of high quality data by practices. This currently includes: IT training initiatives; employing technical support staff in primary care groups; the introduction of standardised coding sets and data input templates; a project to promote the use of practice clinical information systems by the extended primary care team; and supporting the upgrading of practice hardware and software - focusing on a few core clinical information systems. As part of the Health Action Zone priority of reducing inequalities in the delivery of health care, a process of leveling up of practices has been pursued. This effectiveness of this strategy is reflected in the achievement of $100 \%$ coverage in the current MEDICS scheme.

Many GP morbidity collection schemes have set out to explore the use of general practice data in health needs assessment, service planning and commissioning (Daniels, 1995; Pearson et al., 1996; Wilson et al., 1995). This use of the data is also proposed in the new NHS information strategy (NHS Executive, 1998). However, published reports have described only limited uses of the data for this purpose - for example, exposing unexpected variations in prevalence of chronic diseases (Klein, 1996), or contributing to relatively narrow service reviews (Pearson et al., 1996; Wilson et al., 1995). Where the use of general practice data in needs assessment and service planning has been described, the authors noted the limitations of the data and found it difficult to estimate its impact on decision-making (Boydell et al., 1995).

Based on our experience, we agree with others that the current usefulness of GP morbidity data for the needs assessment and planning agenda has been overstated (Scobie et al., 1995). However, the continued improvement in data quality within MEDICS means that there is now much more confidence in the validity of prevalence data, and its use in assessing needs is now being proposed from within primary care. For example, one Northumberland PCG is exploring incorporating chronic disease prevalence data into its formula for funding allocation to practices.

Another key theme was the need to make data collection useful and relevant for participating practices. We believe this is essential to maximise participation in projects and to ensure ownership and use of the information by practices. Practices need to care about the quality of the data. This will only occur if the resulting information is considered useful and relevant to patient care. This requires ongoing dialogue with practices and rigorous pruning of the dataset of unnecessary items.

The last two lessons were reflected in the rephrasing of the objectives of MEDICS in September 1994 . The primary objective became: 'to support and encourage general medical practices to develop information systems which improve their understanding of the health characteristics of their registered population'.

Finally, our experience suggests that collecting data in isolation is unlikely to influence practices. The data must be fedback imaginatively to practices - for example, by showing trends over time and external comparisons with other local practices and national norms - and a dialogue maintained through practice visits. Issues highlighted by the data need to be actively followed up, for example, through focused audits, the development of guidelines or training and education for the primary health care teams.

The lessons from the first two phases of MEDICS have been incorporated into current arrangements for collecting data from general practice in Northumberland. These illustrate three paradigm shifts that have occurred in our thinking about general practice data collection.

The first is a move from the general to the specific. The initial MEDICS dataset included a diverse range of data based more on availability than local and national requirements and priorities. Many of these items have now been dropped. The flexibility of the MEDICS approach has allowed the dataset to be re-aligned. The current dataset is more focused and coherent. It should be more relevant to practices as the core dataset is now closely linked with the Northumberland Heart Health Programme (Northumberland Heart Health Programme Working Party, 1997), a collection of evidence-based guidelines for primary and secondary prevention, and management of ischaemic heart disease and related conditions, such as hyper- 
tension. The MEDICS work and dataset is also closely aligned to the implementation and monitoring of the National Service Framework for Coronary Heart Disease (Department of Health, 2000) in Northumberland.

The MEDICS approach is now being expanded into other priority areas. Work is underway to develop data entry templates for diabetes and stroke, and a pilot project is exploring how the MEDICS approach can be applied to the implementation and monitoring process for the Mental Health National Service Framework. The latter is focusing initially on the creation of registers of patients with severe mental illness, depression and learning disabilities - as a starting point for auditing care for these patients.

Secondly, there has been a shift away from collecting prevalence data to inform needs assessment and commissioning. The project is now focused mainly on improving patient care through better management of information within practices, and hence improving their capacity to deliver structured care. The current dataset includes measures of the quality of care for cardiovascular diseases through simple outcome and process-related indicators. Examples include the proportion of patients with a history of myocardial infarction who are receiving aspirin; the proportion of patients with ischaemic heart disease with raised cholesterol levels; and blood pressure screening amongst the whole population. We believe MEDICS data will be crucial for identifying inequalities in service provision and delivery for the management of conditions like heart disease, and will be an important component of a strategy to address and monitor inequalities in health care provision and performance.

The focus on collecting information to improve individual patient care is in line with national developments, such as clinical governance (Department of Health, 1999). Thus the new NHS information strategy emphasises the importance of the electronic health record and the need for information to support the core purpose of the NHS caring for individuals and supporting the public health (NHS Executive, 1998). The National Service Framework for Coronary Heart Disease stresses the role of GPs and primary health care teams in identifying patients at risk of or with established heart disease and providing appropriate advice and treatment to reduce their risk
(Department of Health, 2000). We believe that this can only be realistically achieved through computerised clinical information systems.

Finally, and most fundamentally, data collection is now no longer seen as part of an exploratory project but rather as a core activity which benefits practices and their patients. In line with this philosophy, payments for providing data have been dropped. Nevertheless, all 53 of practices have agreed to provide data.

Senior managers at the health authority now attach much more importance and credibility to data from general practice. MEDICS is an information project within the wider Northumberland Health Action Zone IM\&T strategy. The need for high quality health information is driving the wider IM\&T agenda, which includes: modernising the primary care IT infrastructure through the installation of local area networks into all practices, provision of network support managers in all primary care groups (PCG), and plans for clinical system trainers in each PCG.

The emergence of clinical governance and the need to implement and monitor national service frameworks has reinforced the importance of maintaining high quality primary care data. The evolution of primary care data collection to a core activity in Northumberland is reflected by its use in setting and monitoring the achievement of targets for clinical governance and national service frameworks. For example, within Northumberland, Primary Care Group Clinical Governance Frameworks emphasise ischaemic heart disease and include targets for the completeness of disease registers, use of evidence-based interventions and recording of risk factors.

By April 2001, over $90 \%$ of patients in Northumberland will be covered by practices on personal medical services (PMS) contracts. These PMS contracts incorporate locally agreed clinical indicators, all drawn from the MEDICS dataset. The local medical committee has also agreed to MEDICS data being used to inform the remuneration process for the chronic disease management component of health promotion activity. In all cases, the achievement of targets will be monitored using routine data on practice clinical systems extracted using MIQUEST. Similarly, the MEDICS dataset and process will be used to monitor delivery of the influenza vaccine within Northumberland practices following the national directive to 
extend coverage to the over-65s and to monitor this process.

\section{Conclusion}

MEDICS is a pioneering project for the collection of data from general practice in the UK. The scheme has evolved over time, drawing on lessons learnt from our experience. The continued existence of the project and large number of practices taking part demonstrates that ongoing morbidity data collection from general practice is feasible, sustainable, and useful to practices. The information generated can be used by practices as a basis for structured disease management and through its use in audit, target setting, performance management, and education should contribute to meeting the requirements of national initiatives and local priorities for improving the quality of care in primary care.

\section{Acknowledgements}

The authors would like to thank all the practices who have participated in MEDICS and to acknowledge the role of MEDICS board members Dr Peter Mitford, Dr Nick Booth, Dr Malcolm Aylett, Dr David Brown and Malcolm Fraser in the establishment of the project.

\section{References}

Allan, K. and Markwell D. on behalf of the MIQUEST Project Board and Project Team. 1994. MIQUEST Project Report. Durham: Northern Regional Health Authority.

Allan, K.J. 1994: Health data collection from general practice: a changing world. Harrogate: BJHC Ltd, 573-79.

Aylett, M., Creighton, P., Whiteside, P., Singleton, S., Redmond, L. and Balsdon, D. 1997: The introduction of local hypertension guidelines. Coronary Health Care 1, 90-93.

Boydell, L., Grandidier, H., Raferty, C., McAteer, C. and Reilly, P. 1995: General practice data retrieval the Northern Ireland project. Journal of Epidemiology and Community Health 49, S22-S25.

Collection of Health Data from General Practice project. 1996: Collection of health data from general practice: overview. Leeds: NHS Executive.

Colver, A.F. 1990: Health surveillance of preschool children: four years' experience. British Medical Journal 300, 1246-48.
Daniels, A. 1995: Buckinghamshire Primary Care Computing (BPCC) progress to December 1994. British Journal of Healthcare Computing and Information Management 12, 1718.

Department of Health. 1993. Computerisation in GP Practices. Leeds: NHS Management Executive.

Department of Health. 1996: Primary Care: Delivering the Future (White paper) with EL(96)112. London: The Stationery Office.

Department of Health. 1997: The New NHS. Modern. Dependable (White paper). London: The Stationery Office.

Department of Health. 1998: The New NHS Modern and Dependable: Developing Primary Care Groups (HSC 1998/139). Leeds: Department of Health.

Department of Health. 1999: Clinical Governance in the New NHS (HSC 1999/065). Leeds: Department of Health.

Department of Health. 2000: National Service Framework for Coronary Heart Disease. London: Department of Health.

Gordon, S. 1991: Prevalence of Diabetes in Northumberland. Morpeth: Northumberland Health Authority.

Klein, L. 1996: Needs assessment in south Cheshire. In: Eames, M., editor, Measuring Morbidity and Health - what Information can General Practice Deliver? Hatfield: University of Hertfordshire, 8-14.

Maguire, S., Rigby, J. and Wainwright, D. 1994: The MEDICS Project Evaluation Study: Final Report. Newcastle upon Tyne: The Newcastle Business School, University of Northumbria at Newcastle.

NHS Executive. 1996a: Clinical Audit in the NHS: Using Clinical Audit in the NHS: A Position Statement. Leeds: NHS Executive.

NHS Executive. 1996b. Promoting Clinical Effectiveness: A Framework for Action in and through the NHS. Leeds: NHS Executive.

NHS Executive. 1998: Information for Health: An Information Strategy for the Modern NHS 1998-2005. Leeds: Department of Health.

NHS Information Management Centre. 1997: General Medical Practice Computer Systems: Requirements for Accreditation. Leeds: NHS Executive.

NHS Management Executive. 1994: Developing NHS Purchasing and GP Fundholding. EL(94)79. Leeds. NHSME.

Northumberland Heart Health Programme Working Party. 1997: Northumberland Heart Health Programme: A Strategy for the Prevention and Treatment of Heart Disease. Morpeth: Northumberland Health Authority.

Northumberland Primary Care Audit Group. 1996: Patients' Records Data Completion Audit. Morpeth: Northumberland PCAG.

Northumberland Primary Care Audit Group. 1997: Re-audit of Hypertension Management. Morpeth: Northumberland PCAG.

Pearson, N., O-Brien, J., Thomas, H., Ewings, P., Gallier, L. and Bussey, A. 1996: Collecting morbidity data in general practice: the Somerset morbidity project. British Medical Journal 312, 1517-20.

Scobie, S., Basnett, I. and McCartney, P. 1995: Can general prac- 
tice data be used for needs assessment and health care planning in an inner-London district? Journal of Public Health Medicine 17, 475-83.

Tudor-Hart, J., 1993: Hypertension: Community Control of High Blood Pressure, 3rd edn. Oxford: Radcliffe Medical Press.
Wilson, A.E., Pollock, C., Weekes, T. and Dowell, A. 1995: Can general practice provide useful information? Evaluation of a primary health care information project in northern England. Journal of Epidemiology \& Community Health 49, 227-30. 